\title{
The Acute Splanchnic and Peripheral Tissue Metabolic Response to Endotoxin in Humans
}

\author{
Yuman Fong, Michael A. Marano, Lyle L. Moldawer, He Wei, Steven E. Calvano, John S. Kenney,“ Anthony C. Allison,” \\ ‡Anthony Cerami, G. Thomas Shires, and Stephen F. Lowry \\ Laboratory of Surgical Metabolism, Department of Surgery, and Clinical Research Center, New York Hospital-Cornell Medical Center, \\ New York 10021; ${ }^{\ddagger}$ Laboratory of Medical Biochemistry, The Rockefeller University, New York 10021; and *Department of \\ Immunology, Syntex Research, Syntex Laboratories, Inc., Palo Alto, California 94303
}

\begin{abstract}
The in vivo alterations in organ-specific substrate processing and endogenous mediator production induced by endotoxin were investigated in healthy volunteers. An endotoxin bolus $(20 \mathrm{U} / \mathrm{kg})$ produced increased energy expenditure, hyperglycemia, hypoaminoacidemia, and an increase in circulating free fatty acids. These changes included increased peripheral lactate and free fatty acid output, along with increased peripheral uptake of glucose. Coordinately, there were increased splanchnic uptake of oxygen, lactate, amino acids, and free fatty acids, and increased splanchnic glucose output. There were no changes in circulating glucagon, or insulin and transient changes in epinephrine and cortisol were insufficient to explain the metabolic changes. Plasma cachectin levels peaked 90 min after the endotoxin infusion, and hepatic venous (HV) cachectin levels (peak $250 \pm 50 \mathrm{pg} / \mathrm{ml}$ ) were consistently higher than arterial levels (peak $130 \pm 30 \mathrm{pg} / \mathrm{ml}, P<0.05$ vs. HV). No interleukin $1 \alpha$ or $1 \beta$ was detected in the circulation. Circulating interleukin 6, measured by B.9 hybridoma proliferation, peaked $2 \mathrm{~h}$ after the endotoxin challenge (arterial, 16 $\pm 2 \mathrm{U} / \mathrm{ml}$ $\mathrm{HV}, 21 \pm 3 \mathrm{U} / \mathrm{ml})$. The net cachectin efflux $(\sim 7 \mu \mathrm{g})$ from the splanchnic organs demonstrates that these tissues are a major site for production of this cytokine. Hence, splanchnic tissues are likely influenced in a paracrine fashion by regional cachectin production and may also serve as a significant source for systemic appearance of this cytokine. (J. Clin. Invest. 1990. 85:1896-1904.) cachectin/tumor necrosis factor • cytokines • glucose $\bullet$ lactate $\bullet$ lipopolysaccharide
\end{abstract}

\section{Introduction}

Invasive infection by gram-negative bacteria elicits significant alterations in energy and substrate metabolism. From animal studies it is apparent that these perturbations of metabolic homeostasis are dependent upon an interaction between peripheral tissue substrate stores and splanchnic organs $(1,2)$. In situations of acute infectious injury or an ongoing inflammatory process, a flow of substrates necessary for gluconeogenesis

Address reprint requests to Dr. Lowry, Laboratory of Surgical Metabolism, New York Hospital-Cornell Medical Center, 525 East 68th Street, F-2016, New York, NY 10021.

Received for publication 6 February 1989 and in revised form 30 November 1989.

J. Clin. Invest.

(c) The American Society for Clinical Investigation, Inc. 0021-9738/90/06/1896/09 \$2.00

Volume 85, June 1990, 1896-1904 and synthesis of acute-phase proteins proceeds from the periphery to the splanchnic organs. The temporal characteristics of this coordinated metabolic response as well as the mechanisms responsible for this response to injury in humans are incompletely understood.

A complex array of host endogenous mediators triggered by infectious stimuli is presumed to produce the constellation of clinical findings associated with infection. The roles of classical hormones such as the catecholamines, cortisol, and glucagon have been studied $(3,4)$. Persistent elevations of combinations of glucagon, epinephrine, or cortisol produced by constant infusions of these hormones mimic some of the changes seen in injury (5-10). However, the correlation between alterations in circulating levels of such hormones and the metabolic changes acutely induced by infection is still poorly characterized.

A class of proteins secreted by activated blood monocytes and tissue histiocytes, collectively termed cytokines, is attracting attention for their role as significant endogenous mediators of infectious injury. One of these cytokines, cachectin/tumor necrosis factor- $\alpha$ (TNF- $\alpha /$ cachectin), ${ }^{1}$ has been frequently detected in the circulation of patients suffering various infections $(11,12)$. Infusions of high doses of cachectin have been associated with counterregulatory hormone responses, shock, and death $(13,14)$. Sublethal infusions of cachectin in animals have resulted in peripheral nitrogen wasting, lactic acidosis, and a hepatic acute-phase protein response $(15,16)$. Furthermore, administration of antibodies specific for cachectin prevented cardiovascular collapse and death in rabbits receiving endotoxin (17), and in primates receiving an otherwise lethal dose of Escherichia coli (18). Administration of antibodies to cachectin during bacteremia also attenuates the appearance of other endogenous mediators such as interleukin 1 (IL-1) and interleukin 6 (IL-6), as well as counterregulatory hormones (19). Thus, cachectin likely plays not only an essential but also proximal role in the mediator response to injury.

In addition to their vital roles in metabolic processes, the splanchnic organs also possess a large store of tissue macrophages capable of producing inflammatory proteins (20). It is hypothesized that cytokines, produced by cells in the splanchnic organs may act in a paracrine fashion to govern local metabolic responses to injury, or may exert effects in distant organs when released from the tissues into the circulation. However, there is no definitive documentation of a splanchnic production of cytokines in vivo and the contribution of the splanchnic pool of macrophages to local and systemic cytokine production remains unclear.

1. Abbreviation used in this paper: TNF, tumor necrosis factor. 
In an effort to address these issues, the present study was designed to assess the regional and systemic alterations in both substrate processing and endogenous mediator production during controlled endotoxemia.

\section{Methods}

Subjects. Six subjects aged $26 \pm 1$ yr and within $10 \%$ of ideal body weight for age, sex, and height (Metropolitan Life Table, 1983) were admitted to the Adult Clinical Research Center of the New York Hospital-Cornell Medical Center after screening by complete physical examination, blood count, serum biochemical analysis, electrocardiogram, and chest roentgenogram. The study was approved by the Institutional Review Board of the New York Hospital-Cornell Medical Center and informed written consent was obtained from each subject before enrollment into the study.

Study protocol. The volunteers were admitted to the Clinical Research Center for a 5-d period. From the time of admission until discharge all subjects were allowed to ambulate within the ward but were restricted from any other physical activity. Subjects were weighed daily at 6 a.m. after voiding. Oral temperatures were monitored every 8 $h$ during a 3-d period of equilibration. During these first $3 \mathrm{~d}$ in the hospital, each subject was fed orally with a defined formula diet (Sustacal, Mead-Johnson \& Co., Evansville, IN) in six equal portions daily. This diet was provided at 1.2 times the measured resting energy expenditure. Feedings were discontinued at $8 \mathrm{p} . \mathrm{m}$. on hospital day 3 when an intravenous infusion of $5 \%$ dextrose $(50 \mathrm{mg} / \mathrm{kg}$ per h) was begun and continued throughout the subsequent study period in order to simulate the clinical situation of dextrose infusions in hospitalized patients.

At 9 a.m. on day 4, a transcutaneous hepatic vein catheter was inserted under fluoroscopic guidance through a femoral site. A retrograde femoral venous catheter and a radial arterial catheter were also placed. The position of the hepatic venous catheter in the right hepatic vein was verified by contrast radiography. Blood pressure, heart rate, rectal temperature, and respiratory rates were continuously monitored. After baseline metabolic rate measurements and blood samplings for substrates, hormones, and monokines, each subject received an intravenous (femoral vein) injection of National Reference Bacterial Endotoxin (Lot EC-5, $20 \mathrm{U} / \mathrm{kg}$ over $5 \mathrm{~min}$ ). The endotoxin was prepared from Escherichia coli 0113 and was provided by Dr. H. D. Hochstein (Office of Biologics, Food and Drug Administration) (21). Repeated measurements for metabolic rate, substrate concentrations, organ substrate flux, hormone levels, and cytokine levels were performed over the next $6 \mathrm{~h}$ as outlined below.

Metabolic rate. Measurements of oxygen consumption $\left(\mathrm{VO}_{2}\right)$, carbon dioxide production $\left(\mathrm{VCO}_{2}\right)$, and minute ventilation were performed in the supine position with a Beckman Metabolic Measurement Cart-1 (Sensormedics Corp., Anaheim, CA). This system contained an OM-11 oxygen analyzer and LB-2 carbon dioxide analyzer. The instrument was calculated before and after each test using a minimum of two standard calibration gases (100\% nitrogen, and 16\%:4\% oxygen/carbon dioxide) (22). Metabolic rate (MR) was estimated using the de V. Weir formula (23): MR (calories per minute) $=3.941 \cdot \mathrm{VO}_{2}$ $+1.106 \cdot \mathrm{VCO}_{2}$.

Extremity and splanchnic blood flow. Extremity blood flow (lower extremity) was performed before and after each blood sampling for substrate concentrations using electrocapacitance plethysmography (24). Splanchnic blood flow was estimated by a primed $(12.5 \mathrm{mg})$ continuous $(0.5 \mathrm{mg} / \mathrm{min})$ intravenous infusion of indocyanine green (25). The infusion was started $1 \mathrm{~h}$ before the endotoxin challenge. Four simultaneous arterial and hepatic venous samples were collected at 5-min intervals immediately before the endotoxin challenge. Simultaneous samples were then collected at half-hour intervals after the endotoxin administration. Blood samples were centrifuged, and the absorbance of the plasma fraction determined at $805 \mathrm{~nm}$. Hematocrits were determined every $2 \mathrm{~h}$ and the estimated splanchnic blood flow
(ESBF, milliliters per minute) calculated as: $\mathrm{ESBF}=\boldsymbol{R} \cdot([\mathrm{art}]$ $-[v e n])^{-1} \cdot(1-H c t)^{-1}$, where $R$ (milligrams per minute) is the dye disappearance rate which is approximated by the dye infusion rate, and [art] - [ven] (milligrams per milliliter) is the arterial-venous difference in dye concentration as determined spectrophotometrically (26).

Splanchnic and extremity $\mathrm{O}_{2}$ consumption. Simultaneous arterial, femoral venous, and hepatic venous blood samples were collected in heparinized syringes at baseline, and at 2,4 , and $6 \mathrm{~h}$ after the endotoxin challenge. Analysis for levels of $\mathrm{PO}_{2}$ and $\mathrm{PCO}_{2}$ were performed using an automated blood gas analyzer (BGM 1312, Instrumentation Laboratory, Lexington, MA). Splanchnic and extremity $\mathrm{O}_{2}$ consumption was calculated as: Blood flow $\cdot\left[(0.34)(H b)\left(\mathrm{O}_{2} \mathrm{Sat}_{\mathrm{art}}-\mathrm{O}_{2} \mathrm{Sat}_{\mathrm{ven}}\right)\right.$ $\left.+(0.031)\left(\mathrm{PO}_{2 a \mathrm{rt}}-\mathrm{PO}_{2 \text { ven }}\right)\right]$, where $\mathrm{Hb}$ is the hemoglobin concentration, and $\mathrm{O}_{2} \mathrm{Sat}$ is the oxygen saturation.

Substrate flux. Arterial, femoral venous, and hepatic venous samples for substrate analysis were drawn simultaneously. Substrate flux was calculated as the product of the arterial-venous difference in substrate concentration and the organ blood flow. A positive value represents a relative uptake across the extremity or splanchnic bed whereas a negative flux indicates an efflux.

Substrate concentrations. Plasma glucose concentrations were determined using an automated glucose analyzer (model 23A, Yellow Springs Instrument Co., Yellow Springs, $\mathrm{OH}$ ) employing the glucose oxidase reaction (27). Whole blood was immediately precipitated in ice-cold perchloric acid and stored at $-70^{\circ} \mathrm{C}$ until analysis by an enzymatic assay for lactate concentration (28). Plasma free fatty acid concentration was determined on heparinized plasma by the method of Dole and Meinertz (29). Plasma triglyceride concentrations were determined enzymatically (30). Plasma amino acids were determined by anion exchange chromatography on an HPLC system (Perkin-Elmer Corp., Norwalk, CT) using a three-buffer lithium system with norleucine as an internal standard (31) and a Pickering post-column ninhydrin detection system (Pickering Laboratories, Mountain View, CA).

Hormones. Cortisol (32) and insulin (33) were measured by radioimmunoassay on specimens collected in tubes containing EDTA. Plasma for glucagon was collected with EDTA and aprotinin before analysis by radioimmunoassay (34). Epinephrine levels were determined by radioenzymatic assays (35) on specimens collected in tubes containing EGTA and reduced glutathione. Arterial specimens were used for all determinations of hormone levels.

Cytokines. Simultaneous arterial and hepatic venous blood samples at baseline, and at 15-min intervals after the endotoxin challenge were collected in heparinized tubes. These were immediately centrifuged at $4^{\circ} \mathrm{C}$ to separate the plasma, which was stored at $-70^{\circ} \mathrm{C}$ until determination of cachectin level by a previously described ELISA (36). The lower limits of detection for this ELISA is $34 \mathrm{pg} / \mathrm{ml}$.

Plasma was assayed for IL- $1 \alpha$ and IL-1 $\beta$ using monoclonal antibodies specific for either IL- $1 \alpha$ or IL-1 $\beta$ and two-site ELISAs as published for IL-1 $\beta$ (37). The detection limits in plasma of IL- $1 \alpha$ and IL-1 $\beta$ were 56 and $31 \mathrm{pg} / \mathrm{ml}$, respectively.

IL-6 levels were also measured using the murine hybridoma cell line B9 (38). Briefly, serial dilutions of heat-inactivated $\left(56^{\circ} \mathrm{C}\right.$ for 30 min) plasma were incubated in triplicate with 2,000 B.9 cells for $84 \mathrm{~h}$ in 96-well microtiter plates. 3-(4,5-Dimethyl-thiazol-2-yl)2,5-diphenyltetrazolium bromide (MTT, $300 \mu \mathrm{g} / \mathrm{ml}$ ) was added; $3 \mathrm{~h}$ later the supernatant was removed and the cells lysed with isopropanol- $0.004 \mathrm{~N}$ $\mathrm{HCl}$. Cell proliferation was estimated colorimetrically in an ELISA plate reader $(570,690 \mathrm{~nm})$. One unit is half-maximal stimulation of B.9 proliferation.

Statistical analysis. All data are expressed as means \pm SEM. Standard paired Student's $t$ tests were used for single comparisons. ANOVA and Newman-Keuls tests, where appropriate, were used to identify statistical significance for multiple comparisons.

\section{Results}

Vital signs (Fig. 1). A single intravenous bolus of endotoxin at $20 \mathrm{U} / \mathrm{kg}$ produced a pyrogenic response in the volunteers 

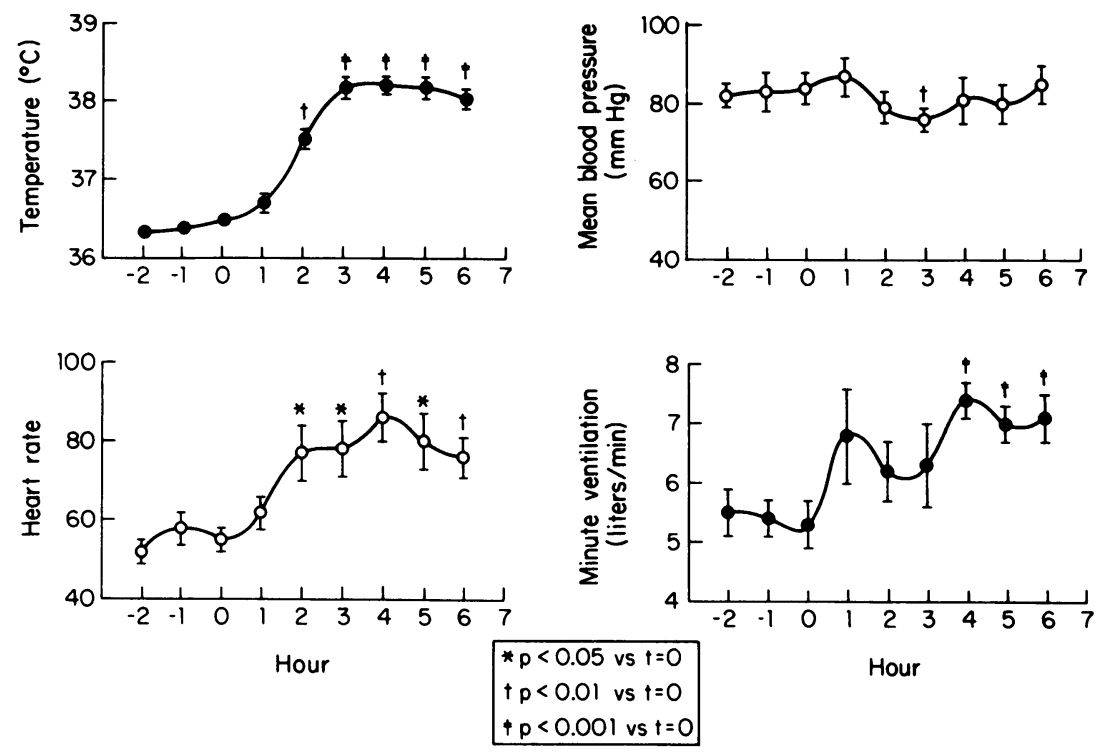

Figure 1. Vital signs: temperature, heart rate, mean blood pressure, and minute ventilation immediately before $(t=0)$ and after the endotoxin challenge. Time is shown in hours.

within $90 \mathrm{~min}$. This fever was sustained for the duration of the study period. A tachycardia was also noted within 90 min of the LPS infusion. Mean blood pressure was unchanged in response to this dose of LPS.

Organ blood flow (Table I). Splanchnic blood flow at baseline was $1.23 \pm 0.07$ liters $/ \mathrm{min}$, similar to previously reported values (39). Within $1 \mathrm{~h}$ after the endotoxin infusion, splanchnic blood flow increased significantly, peaking $3 \mathrm{~h}$ after the endotoxin infusion at $91 \%$ higher than baseline. No significant change in extremity blood flow occurred in response to the endotoxin infusion.

Oxygen consumption (Table I). Total body oxygen consumption increased significantly $(28 \%, P<0.05$ vs. basal) within $2 \mathrm{~h}$ after the endotoxin infusion and continued to rise.
The total body oxygen consumption remained elevated ( $40 \%$, $P<0.01$ vs. basal) at the six hour time point. Coordinately, the splanchnic oxygen extraction increased significantly $(64 \%, P$ $<0.01$ vs. basal) within $2 \mathrm{~h}$ but declined to baseline values by the 6-h time point. At the height of the increase in splanchnic metabolic activity ( $2 \mathrm{~h}$ after the endotoxin challenge) the estimated splanchnic oxygen consumption increased from $34 \%$ of total body $\mathrm{O}_{2}$ consumption (baseline) to $43 \%$ of total body $\mathrm{O}_{2}$ consumption. This mimics the disproportionate increase in splanchnic $\mathrm{O}_{2}$ consumption compared with total body $\mathrm{O}_{2}$ consumption seen in septic humans (39). Extremity oxygen extraction remained unchanged until the 6-h time point when it decreased. The continued elevated total body oxygen consumption at the 6-h time point probably reflects both the in-

Table I. Blood Flow, Oxygen Utilization, and Metabolic Rate in Subjects before $(t=0)$ and after Endotoxin Administration

\begin{tabular}{|c|c|c|c|c|c|c|c|}
\hline & \multicolumn{7}{|c|}{ Time } \\
\hline & \multicolumn{7}{|c|}{$\min$} \\
\hline & 0 & 60 & 120 & 180 & 240 & 300 & 360 \\
\hline \multicolumn{8}{|l|}{ Blood flow } \\
\hline Splanchnic (liters/min) & $1.2 \pm 0.1$ & $1.4 \pm 0.1^{*}$ & $2.3 \pm 0.2^{\ddagger}$ & $2.4 \pm 0.3^{*}$ & $2.0 \pm 0.1^{\ddagger}$ & $1.7 \pm 0.2^{*}$ & $1.6 \pm 0.2$ \\
\hline \multirow[t]{4}{*}{ Extremity $\left(\mathrm{ml} / \mathrm{min}\right.$ per $100 \mathrm{~cm}^{3}$ tissue $)$} & $1.8 \pm 0.3$ & $2.4 \pm 0.2$ & $1.6 \pm 0.2$ & $1.8 \pm 0.2$ & $2.4 \pm 0.3$ & $2.2 \pm 0.5$ & $2.3 \pm 0.3$ \\
\hline & & \multicolumn{6}{|c|}{ Time } \\
\hline & & \multicolumn{6}{|c|}{$\min$} \\
\hline & & \multicolumn{2}{|c|}{$\mathbf{0}$} & 120 & \multicolumn{2}{|c|}{240} & 360 \\
\hline \multicolumn{8}{|l|}{$\mathrm{O}_{2}$ consumption and metabolic rate } \\
\hline \multicolumn{2}{|c|}{ Splanchnic $\mathrm{O}_{2}$ extraction $(\mathrm{ml} / \mathrm{min})$} & \multicolumn{2}{|c|}{$61 \pm 5$} & $100 \pm 13^{\ddagger}$ & \multicolumn{2}{|c|}{$90 \pm 12^{*}$} & $72 \pm 14$ \\
\hline \multicolumn{2}{|c|}{ Extremity $\mathrm{O}_{2}$ extraction $\left(\mu \mathrm{l} / \mathrm{min}\right.$ per $100 \mathrm{~cm}^{3}$ tissue $)$} & \multicolumn{2}{|c|}{$125 \pm 26$} & $126 \pm 18$ & \multicolumn{2}{|c|}{$117 \pm 9$} & $80 \pm 7^{*}$ \\
\hline \multicolumn{2}{|c|}{$\mathrm{VO}_{2}(\mathrm{ml} / \mathrm{min})$} & \multicolumn{2}{|c|}{$181 \pm 17$} & $232 \pm 24^{*}$ & \multicolumn{2}{|c|}{$265 \pm 26^{\ddagger}$} & $253 \pm 21^{\ddagger}$ \\
\hline \multicolumn{2}{|l|}{ MR ( kcal/kg per d) } & \multicolumn{2}{|c|}{$16.4 \pm 1.1$} & $19.4 \pm 0.9$ & \multicolumn{2}{|c|}{$22.5 \pm 0.9^{*}$} & $21.4 \pm 0.7^{\ddagger}$ \\
\hline
\end{tabular}

Values are means $\pm \mathrm{SE}$. Abbreviations: $\mathrm{VO}_{2}$, total body $\mathrm{O}_{2}$ consumption; $\mathrm{MR}$, metabolic rate. ${ }^{*} P<0.05$ vs. $t=0$; ${ }^{\ddagger} P<0.01$ vs. $t=0$; ${ }^{\S} P<0.05$ vs. $t=120$. 
creased energy needs of the respiratory musculature secondary to the increase in minute ventilation and futile cycling secondary to the persistent fever at this time point (40).

Glucose metabolism (Fig. 2). The endotoxin infusion produced a progressive hyperglycemia by $2 \mathrm{~h}(P<0.05$ vs. basal $)$ that persisted through the $6 \mathrm{~h}$ of the study. Associated with this hyperglycemia was an increase in extremity glucose uptake. There was also a persistent increase in net glucose output from the splanchnic bed between 2 and $6 \mathrm{~h}$ after the endotoxin challenge $(P<0.05$ vs. basal).

The arterial lactate levels did not change in response to the endotoxin challenge (Fig. 2). However, a persistent increase in lactate efflux from the extremity was noted between 4 and $6 \mathrm{~h}$ after the endotoxin infusion ( $P<0.05$ vs. basal). Coincidentally there was an increase in splanchnic uptake of this three carbon substrate, peaking $2 \mathrm{~h}$ after the endotoxin infusion, and persisting through the 6-h time point.

Amino acid metabolism (Table II). At baseline, the concentrations of all amino acids except glutamate were higher in hepatic venous drainage than in the arterial circulation (41). An arterial total hypoaminoacidemia followed endotoxin administration $(P<0.05$ at 2 and $4 \mathrm{~h}$ vs. basal). This effect was most prominent for the essential amino acids and for glutamine and alanine. The reduction in circulating amino acid levels was associated with no changes in peripheral amino acid flux. By contrast, splanchnic amino acid uptake, particularly

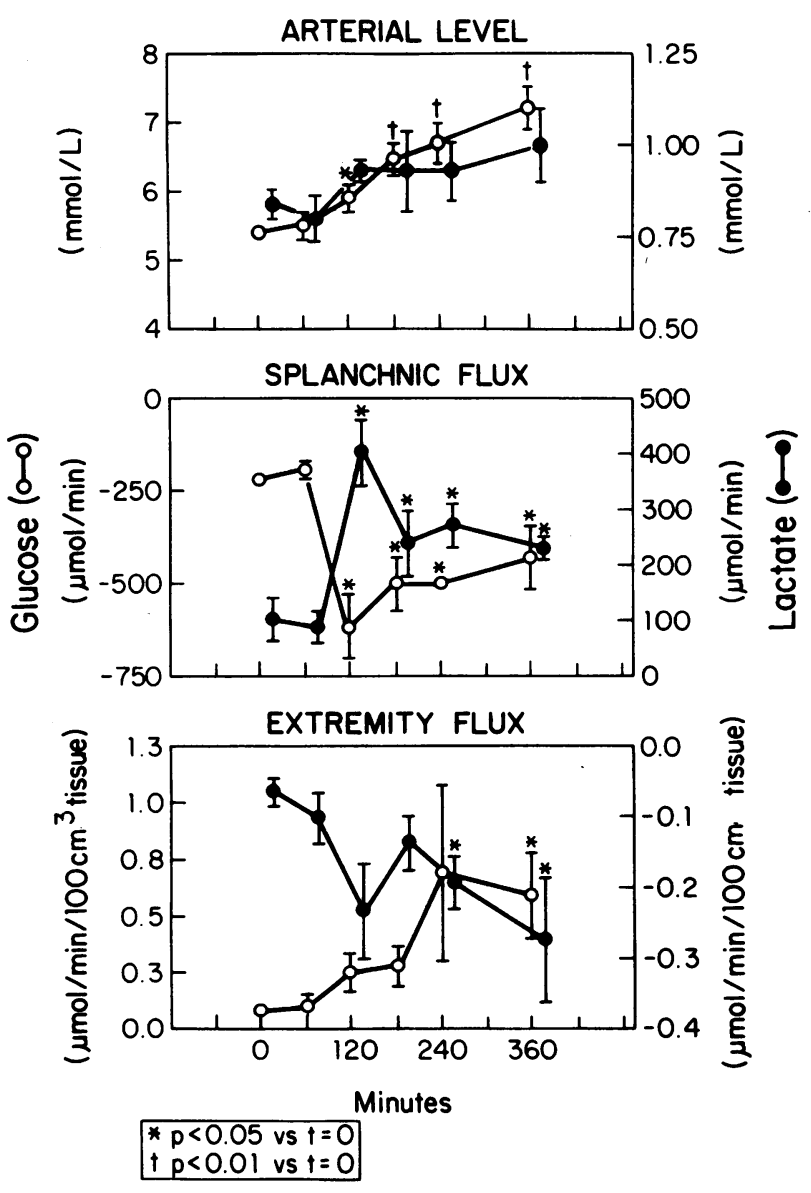

Figure 2. Arterial levels, splanchnic flux, and extremity flux of glucose and lactate. The units for glucose are shown on the left axis. A positive value in flux indicates net uptake of the substrate. of glutamine and alanine, increases significantly $(P<0.05$ vs. basal) between 2 to $6 \mathrm{~h}$ after the endotoxin challenge.

Lipid metabolism. Arterial free fatty acid (FFA) levels increased throughout the $6 \mathrm{~h}$ after the endotoxin challenge (Table III), and were associated with an increase in net efflux of FFA from the extremity $(P<0.01 \mathrm{vs.} \mathrm{basal})$. An increase in hepatic uptake of FFA and a transient increase in efflux of triglycerides from the splanchnic bed at $2 \mathrm{~h}$ after the endotoxin infusion were also observed.

Hormonal changes (Table IV). Arterial cortisol levels increased significantly $(P<0.01)$ within $2 \mathrm{~h}$ after the endotoxin challenge and persisted through $6 \mathrm{~h}$ at elevated levels. Arterial epinephrine was only transiently elevated between 1 and $2 \mathrm{~h}(P$ $<0.05$ ) after the endotoxin bolus, while glucagon and insulin levels did not change in response to the endotoxin infusion.

Cachectin. Arterial levels of cachectin were detectable within $45 \mathrm{~min}$ after the endotoxin challenge, peaked by 90 min, and were undetectable by $180 \mathrm{~min}$ after the endotoxin infusion (Fig. 3). The hepatic venous cachectin levels were significantly higher than the arterial levels whenever this protein was detectable in the circulation. A net splanchnic cachectin efflux was calculated by multiplying the arterial-hepatic venous level differences of cachectin by the estimated splanchnic blood flow (Fig. 3). When this net splanchnic production of cachectin was integrated over time, it was estimated that $\sim 7 \mu \mathrm{g}$ of cachectin were released into the systemic circulation from the splanchnic bed in response to the current dose of endotoxin. This is equivalent to the lowest doses currently tested as cancer chemotherapy $(42,43)$. The half-life of the recombinant protein in circulation of cancer patients receiving TNF as chemotherapy is estimated as 14-16 min, while the volume of distribution of the recombinant protein was estimated as 30-60 liters (43). By using these values, a rough estimate of total body TNF production may be obtained from the arterial concentrations of the protein after endotoxin challenge assuming first-order decay kinetics. By optimizing the production rate per minute over $t=30$ to $t=150$ after LPS challenge and using numerical integration, the total production of TNF is estimated to be 13-26 $\mu \mathrm{g}$ for the current endotoxin dose. Thus, approximately one-half to one-quarter of the total body cachectin production likely comes from the splanchnic tissues.

$I L-1$. IL- $1 \alpha$ and IL-1 $\beta$ were only detected in the hepatic venous plasma of one volunteer at $3 \mathrm{~h}$ after endotoxin challenge (IL- $1 \alpha, 490 \pm 36 \mathrm{pg} / \mathrm{ml}$; IL- $1 \beta, 822 \pm 54 \mathrm{pg} / \mathrm{ml}$ ). IL- $1 \alpha$ or IL- $\beta$ was not detected in any other plasma sample before or within $6 \mathrm{~h}$ after endotoxin challenge. To test for the possible interference of plasma components with IL-1 detection, recombinant IL- $1 \alpha$ or IL- $1 \beta$ was added to IL-1-negative plasmas and then assayed. Over a concentration range of 9.8-2,500 $\mathrm{pg} / \mathrm{ml}$, mean recovery as measured by ELISA was consistently $>82 \%$ for both IL- $1 \alpha$ and IL- $1 \beta$.

$I L-6$. IL-6 levels as measured by the B9 hybridoma proliferation bioassay increased rapidly after endotoxin challenge, peaking at $2 \mathrm{~h}$, and returning to baseline by $6 \mathrm{~h}$ (Table V). The hepatic venous levels were not significantly different than the arterial levels.

\section{Discussion}

The essential role of the liver and other splanchnic organs in the metabolic and overall response to injury has been inferred 


\begin{tabular}{|c|c|c|c|c|}
\hline & \multicolumn{4}{|c|}{ Time } \\
\hline & \multicolumn{4}{|c|}{$\min$} \\
\hline & 0 & 120 & 240 & 360 \\
\hline & \multicolumn{4}{|c|}{$n m o l / m l$} \\
\hline \multicolumn{5}{|l|}{ Arterial amino acid levels } \\
\hline Total amino acids & $2,996 \pm 167$ & $2,347 \pm 118^{*}$ & $2,426 \pm 51^{*}$ & $2,659 \pm 113$ \\
\hline Essential amino acids & $979 \pm 65$ & $805 \pm 45^{*}$ & $800 \pm 45^{*}$ & $825 \pm 51$ \\
\hline Branched chain amino acids & $462 \pm 39$ & $396 \pm 34$ & $401 \pm 33$ & $393 \pm 33$ \\
\hline Glutamine & $564 \pm 29$ & $441 \pm 26^{*}$ & $432 \pm 10^{\ddagger}$ & $510 \pm 16^{\ddagger}$ \\
\hline \multirow[t]{4}{*}{ Alanine } & $304 \pm 44$ & $221 \pm 22$ & $229 \pm 17$ & $296 \pm 39$ \\
\hline & \multicolumn{4}{|c|}{ Time } \\
\hline & \multicolumn{4}{|c|}{$\min$} \\
\hline & 0 & 120 & 240 & 360 \\
\hline & & & & \\
\hline \multicolumn{5}{|l|}{ Hepatic amino acid flux } \\
\hline Total amino acids & $375 \pm 108$ & $719 \pm 68^{*}$ & $615 \pm 48$ & $630 \pm 70$ \\
\hline Essential amino acids & $96 \pm 38$ & $217 \pm 4^{*}$ & $101 \pm 74$ & $186 \pm 26$ \\
\hline Branched chain amino acids & $26 \pm 14$ & $71 \pm 12$ & $75 \pm 21$ & $55 \pm 12$ \\
\hline Glutamine & $85 \pm 23$ & $168 \pm 16^{*}$ & $128 \pm 9$ & $104 \pm 12$ \\
\hline \multirow[t]{4}{*}{ Alanine } & $112 \pm 22$ & $196 \pm 20^{*}$ & $209 \pm 4^{\ddagger}$ & $213 \pm 26^{*}$ \\
\hline & \multicolumn{4}{|c|}{ Time } \\
\hline & \multicolumn{4}{|c|}{$\min$} \\
\hline & 0 & 120 & 240 & 360 \\
\hline & \multicolumn{4}{|c|}{ nmol/min per $100 \mathrm{~cm}^{3}$ tissue } \\
\hline \multicolumn{5}{|l|}{ Extremity amino acid flux } \\
\hline Total amino acids & $-516 \pm 153$ & $-606 \pm 207$ & $-334 \pm 77$ & $-405 \pm 88$ \\
\hline Essential amino acids & $-96 \pm 30$ & $-153 \pm 46$ & $-117 \pm 43$ & $-103 \pm 26$ \\
\hline Branched chain amino acids & $-30 \pm 11$ & $-60 \pm 16$ & $-9 \pm 29$ & $-35 \pm 10$ \\
\hline Glutamine & $-125 \pm 38$ & $-138 \pm 38$ & $-92 \pm 33$ & $-82 \pm 45$ \\
\hline Alanine & $-122 \pm 33$ & $-147 \pm 39$ & $-134 \pm 26$ & $-142 \pm 25$ \\
\hline
\end{tabular}

Values are means \pm SE. Total amino acids include all amino acids except citrulline, asparagine, and ornithine. A positive $(+)$ flux indicates net uptake of amino acids; a negative $(-)$ flux indicates net efflux. Time 0 is immediately before endotoxin administration. ${ }^{*} P<0.05$ vs. $t=0$; ${ }^{\ddagger} P<0.01$ vs. $t=0 ;{ }^{8} P<0.05$ vs. $t=120$.

from clinical data demonstrating that liver dysfunction in injury is associated with a markedly higher mortality rate (44), and the ability to increase oxygen delivery to the splanchnic organs in sepsis correlates with a lower mortality (45). Previous studies of bacteremic burn patients have demonstrated that splanchnic metabolic alterations including increases in blood flow, oxygen uptake, glucose output, lactate uptake, and uptake of the gluconeogenic amino acids accompany injury (46). Such increases in splanchnic metabolic activity have also been observed in septic surgical patients (39). Although these previous studies suggest an essential role for the splanchnic bed in the hypermetabolism, hyperglycemia, hypoaminoacidemia, and hyperlipidemia that accompany injury, the multitude of stimuli encountered in the critically ill patients examined in these studies proscribe attributing any direct cause-effect relationship for any single stimulus. Specifically, the relative con- tribution of the endotoxemia/bacteremia associated with infection (47-49) cannot be clearly discerned from these studies. Furthermore, no study has examined the acute splanchnic changes that occur after infectious injury. The current study demonstrates that exposure to even a small dose of endotoxin acutely reproduces many of the splanchnic metabolic responses associated with injury. Additionally, the splanchnic production of the cytokine cachectin demonstrates that regional tissue capacity for cytokine production may vary in response to endotoxin challenge and that this regional cytokine production may be important in the local and systemic changes during injury.

Using selected venous cannulations, we demonstrate that rapid alterations, occurring in both peripheral skeletal muscle and the splanchnic organs, combine to produce the clinical picture of acute endotoxemic injury. The peripheral metabolic 


\begin{tabular}{|c|c|c|c|c|}
\hline & \multicolumn{4}{|c|}{ Time } \\
\hline & \multicolumn{4}{|c|}{$\min$} \\
\hline & 0 & 120 & 240 & 360 \\
\hline \multicolumn{5}{|l|}{ FFA } \\
\hline Arterial levels (meq/liter) & $0.25 \pm 0.05$ & $0.58 \pm 0.08^{*}$ & $0.71 \pm 0.09^{\ddagger}$ & $0.68 \pm 0.05^{\ddagger}$ \\
\hline Splanchnic flux $(\mu e q / \mathrm{min})$ & $68 \pm 22$ & $388 \pm 95^{*}$ & $363 \pm 70^{*}$ & $300 \pm 81$ \\
\hline \multirow[t]{4}{*}{ Extremity flux (neq/min per $100 \mathrm{~cm}^{3}$ tissue) } & $-73 \pm 30$ & $-227 \pm 77$ & $-388 \pm 58^{\ddagger}$ & $-353 \pm 56^{\ddagger}$ \\
\hline & \multicolumn{4}{|c|}{ Time } \\
\hline & \multicolumn{4}{|c|}{$\min$} \\
\hline & 0 & 120 & 240 & 360 \\
\hline \multicolumn{5}{|l|}{ Triglyceride } \\
\hline Arterial levels $(\mathrm{mmol} / \mathrm{dl})$ & $1.7 \pm 0.1$ & $1.8 \pm 0.2$ & $1.8 \pm 0.2$ & $1.6 \pm 0.2$ \\
\hline Splanchnic flux $(\mu \mathrm{mol} / \mathrm{min})$ & $-60 \pm 40$ & $-180 \pm 70^{*}$ & $-64 \pm 10$ & $-50 \pm 60$ \\
\hline Extremity flux ( $\mathrm{nmol} / \mathrm{min}$ per $100 \mathrm{~cm}^{3}$ tissue) & $7 \pm 70$ & $-63 \pm 70$ & $11 \pm 90$ & $-75 \pm 73$ \\
\hline
\end{tabular}

Values are means \pm SE. For flux determinations, a positive value indicates net uptake, and a negative value indicates efflux. Time is shown in minutes after the endotoxin challenge. $t=0$ is immediately before endotoxin administration. ${ }^{*} P<0.05$ vs. $t=0 ;{ }^{\ddagger} P<0.01$ vs. $t=0$.

responses to the current endotoxin bolus included an extremity FFA efflux and an extremity lactate efflux that was independent of alterations in extremity blood flow or extremity oxygen consumption. Simultaneously, there was an increase in splanchnic oxygen consumption, uptake of FFA and the gluconeogenic substrates lactate and alanine, and an increase in splanchnic efflux of glucose. These data are consistent with the increase in whole-body lipolysis and fat utilization observed in injury $(50,51)$. The mobilization of FFA from the peripheral stores is an important adaptive response in injury (52) that along with the peripheral mobilization of three-carbon and nitrogenous substrates provides oxidative fuel and substrate for hepatic triglyceride (53), glucose, and protein synthesis. The splanchnic metabolic alterations seen in the current study are particularly favorable for splanchnic glucose production and emphasize the important role of the splanchnic bed, as the major store of glycogen and the major site of gluconeogenesis (54), in regulation of circulating glucose levels.

Metabolic changes after infectious injury have long been attributed to changes in circulating counterregulatory hormones (4-9, 32). After the current endotoxin challenge, the only counterregulatory hormone demonstrating a persistent change in circulating level was cortisol. Although sustained increases in circulating cortisol levels produce an acute increase in peripheral tissue efflux of amino acids (10) as well as increased levels of circulating amino acids (55), neither of these changes in amino acid metabolism was noted in the current study. Additionally, cortisol alone does not significantly effect splanchnic glucose production (3). Thus it is unlikely that the elevation of cortisol alone was responsible for the increased splanchnic glucose production or for other metabolic changes documented in the current study. These counterregulatory hormones are likely more important in the chronic stages of infectious injury, or in more severe acute injury than that seen in the current study.

In vitro as well as animal studies have identified effects attributable to cachectin that may influence several of the metabolic changes seen after endotoxin challenge. In the L-6 myoblast, cachectin stimulates glucose uptake and increased lactate production (56). Administration of cachectin to animals also produces increased lactate efflux from the periphery (13), increased glucose turnover in splanchnic organs (57), as

Table IV. Hormonal Profile before $(t=0)$ and after the Endotoxin Challenge

\begin{tabular}{|c|c|c|c|c|c|c|c|}
\hline & \multicolumn{7}{|c|}{ Time } \\
\hline & & & & $\min$ & & & \\
\hline & 0 & 60 & 120 & 180 & 240 & 300 & 360 \\
\hline Cortisol $(n g / m l)$ & $130 \pm 50$ & $177 \pm 44$ & $313 \pm 32^{\ddagger}$ & $345 \pm 37^{\ddagger}$ & $324 \pm 27^{\ddagger}$ & $271 \pm 20^{\ddagger}$ & $204 \pm 27^{*}$ \\
\hline Epinephrine $(p g / m l)$ & $83 \pm 28$ & $236 \pm 61^{*}$ & $208 \pm 32^{*}$ & $180 \pm 48$ & $111 \pm 17$ & $107 \pm 8$ & $101 \pm 23$ \\
\hline Glucagon $(p g / m l)$ & $161 \pm 26$ & ND & $189 \pm 39$ & ND & $137 \pm 17$ & ND & $140 \pm 19$ \\
\hline Insulin $(\mu U / m l)$ & $15 \pm 3$ & $13 \pm 2$ & $11 \pm 3$ & $14 \pm 3$ & $12 \pm 2$ & $16 \pm 4$ & $24 \pm 8$ \\
\hline
\end{tabular}

Values are means \pm SE. ${ }^{*} P<0.05$ vs. $t=0 ;{ }^{\ddagger} P<0.01$ vs. $t=0$; ND, not determined. 
ARTERIAL AND HEPATIC VENOUS CACHECTIN LEVELS

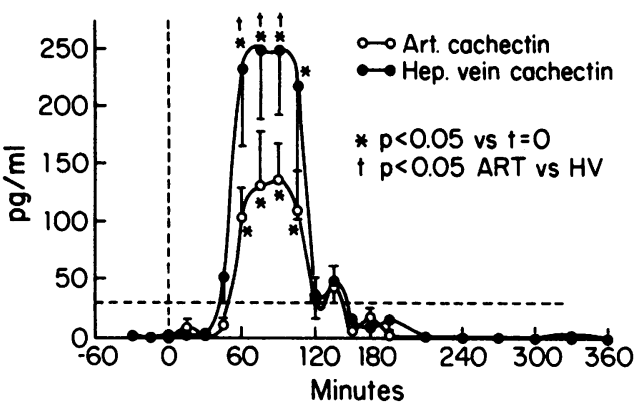

SPLANCHNIC CACHECTIN EFFLUX

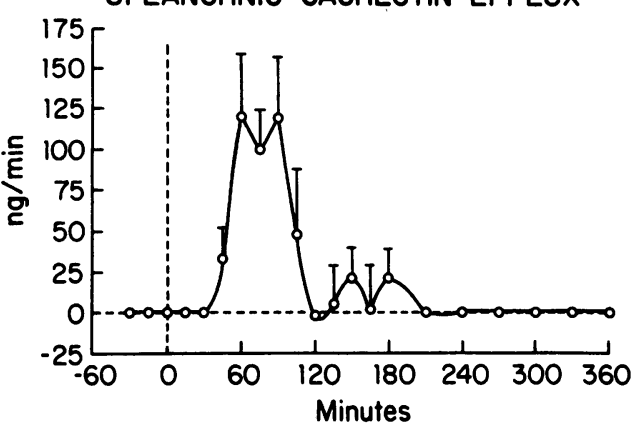

Figure 3. Circulating cachectin levels and splanchnic cachectin efflux. Arterial (Art.) and hepatic venous (Hep. vein) cachectin concentrations in response to the endotoxin challenge is illustrated in the top panel. The broken line indicates the lower limits of detection for the cachectin assay. Splanchnic cachectin efflux calculated as [(Art.) - (Hep. vein)] $\times$ Splanchnic plasma flow is illustrated in the lower panel. $t=0$ is the measurement immediately before the endotoxin injection. Numerical integration of the splanchnic cachectin efflux curve indicates that $\sim 7 \mu \mathrm{g}$ of cachectin is released.

well as increased hepatic uptake of the amino acid analogue amino-isobutyric acid (58), lipolysis (42), triglyceride production, and hepatic lipogenesis (59). Of note is the fact that transient appearance of cachectin in the circulation of the human, as produced by bolus injections of this cytokine during cancer chemotherapy, is sufficient to produce many of the physiologic effects associated with this molecule $(42,43,60)$. In the current study, the temporal relationship between cachectin production and the metabolic changes (increased extremity lactate output, increased hepatic glucose production, and increased hepatic amino acid uptake) strongly suggest a role for this cytokine or the mediator cascade triggered by this cytokine in the acute

Table V. Arterial and Hepatic Venous IL-6 Levels

\begin{tabular}{lccccc}
\hline & \multicolumn{5}{c}{ Time } \\
\cline { 2 - 6 } \multicolumn{1}{c}{ Level } & 0 & 120 & $\min$ & 240 & 360 \\
\hline \multirow{5}{c}{$U / m l$} \\
Arterial & $0.6 \pm 0.4$ & $16.0 \pm 1.7^{*}$ & $5.2 \pm 0.9^{*}$ & $1.2 \pm 0.5$ \\
Hepatic venous & $0.0 \pm 0.0$ & $20.8 \pm 3.0^{*}$ & $5.4 \pm 1.0^{*}$ & $0.0 \pm 0.0$ \\
\hline
\end{tabular}

Means \pm SEM. ${ }^{*} P<0.05$ vs. $t=0$. B9 proliferation measured in units of hybridoma growth factor per milliliter. metabolic responses to endotoxemia. Given the inherent toxicities of cachectin, as evidenced by animal studies and by observations in tumor-bearing patients receiving cachectin as cancer chemotherapy, use of infusions of cachectin in normal subjects or use of highly invasive hepatic vein catheterizations in patients receiving cachectin cannot be justified. Furthermore, no antibody to cachectin is currently available for human use. Thus, definitive proof of the role for this cytokine as a principal inducer of metabolic changes during injury is lacking in humans. Nevertheless, the data from both animal and patient studies as well as the recent observations that monoclonal antibodies to cachectin not only block propagation of the mediator cascade, but also block the acute metabolic alterations accompanying bacteremia in primates (19) strongly support the concept that cachectin is a pivotal mediator after infectious injury.

It is clear that production of cytokines in vivo may occur in a variety of tissues. Gene transcription for cachectin/TNF is increased at numerous sites including liver, kidney, lung, and spleen after endotoxin injection in rodents (61). Gene transcription for IL-1 is also increased following injury at many tissue sites (62). Production of cytokines at the various tissues may vary depending upon the location of the injurious stimulus. In meningitis, for example, levels of cachectin/TNF (63) or IL-6 (64) are decidedly higher in the cerebrospinal fluid than in the systemic circulation. Additionally, intratracheal administration of LPS in experimental models is associated with significant increases in the TNF levels in the bronchoalveolar lavage fluid but no detection of this cytokine in the circulation whereas administration of LPS intravenously increased circulating levels without effecting cytokine levels in the bronchoalveolar lavage fluid (65). The splanchnic bed contains a large number of tissue macrophages such as the hepatic Kupffer cells, which are capable of producing cytokines such as cachectin in vitro (20). Hence, in response to an appropriate stimulus such as LPS, this splanchnic pool of macrophages may produce cytokines in sufficient quantity to influence local splanchnic metabolic processes. An overflow of such regionally produced cytokines into the systemic circulation may further influence whole body homeostasis. The present study is the first demonstration in humans that the splanchnic bed may be a significant source of cytokine production in vivo. Furthermore, the current study demonstrates that differential rates of cachectin production by various tissues, or "compartmentalized" production of cytokines, may occur in response to a controlled systemic stimulus.

Although endotoxin is a potent inducer of $\mathrm{IL}-1$ production by monocytes and macrophages in vitro, little or no IL-1 $\alpha$ or IL- $1 \beta$ was detected in the circulation up to $6 \mathrm{~h}$ after endotoxin challenge. The failure to observe increased circulating levels of IL-1 in human subjects does not appear to be the result of IL-1 binding to $\alpha_{2}$-macroglobulin, IL-1 degradation, or other interfering substances since recombinant IL-1 added directly to plasma was recoverable by ELISA. These data suggest that circulating forms of IL-1 may not be primarily responsible for the acute response to endotoxin in man.

Other cytokines and hormones certainly participate in these acute responses to endotoxin. In addition to cachectin, IL-6 levels also acutely rise in response to endotoxin challenge (66). Cytokines such as interferon- $\gamma$ (67), or macrophage inflammatory protein (68) have also been suggested to partici- 
pate in the host response to injury. The roles of these and other mediators, as well as the synergistic interactions between these cytokines and classical hormones in injury require further investigations.

The current study is a clear demonstration of the essential role the splanchnic organs play in the acute metabolic responses to endotoxin. It is increasingly evident that a complex cascade of endogenous mediators, including cytokines and classic counterregulatory hormones, orchestrate these responses to endotoxemia. Although the exact roles and interactions of the various mediators require further investigation, the current study is the first demonstrating that endotoxin alone is sufficient in producing the splanchnic metabolic alterations associated with severe injury. Furthermore, the demonstration of splanchnic production of cachectin provides evidence that compartmentalized production of cytokines may be important in the natural course of disease.

\section{Acknowledgments}

We thank Diane S. Bushman, Susette M. Coyle, Christopher P. Keogh, and Marvin P. Masada for their expert assistance.

This study was supported in part by grants GM-34695, KO4GM00505, RR-00047, GM-40586, 5P50-GM26145, and AI-21359 from the National Institutes of Health, and by a clinical fellowship from the American Cancer Society.

\section{References}

1. Elwyn, D. H., H. C. Parikh, and W. C. Shoemaker. 1968. Amino acid movements between gut, liver, and periphery in unanesthetized dogs. Am. J. Physiol. 215:1260-1275.

2. Wolfe, J. E., E. N. Bergman, and H. H. Williams. 1972. Net metabolism of plasma amino acids by liver and portal-drained viscera of fed sheep. Am. J. Physiol. 223:438-446.

3. Eigler, N., L. Sacca, and R. S. Sherwin. 1979. Synergistic interactions of physiologic increments of glucagon, epinephrine, and cortisol in the dog. J. Clin. Invest. 63:114-123.

4. Wilmore, D. W., J. M. Long, A. D. Mason, R. W. Skreen, and B. A. Pruitt. 1974. Catecholamines: mediator of the hypermetabolic response to thermal injury. Ann. Surg. 180:653-668.

5. Gelfand, R. A., D. E. Matthews, D. M. Bier, and R. S. Sherwin. 1984. Role of counterregulatory hormones in the catabolic response to stress. J. Clin. Invest. 74:2238-2248.

6. Felig, P., J. Wahren, and R. Hendler. 1976. Influence of physiologic hyperglucagonemia on basal and insulin-inhibited splanchnic glucose output in normal man. J. Clin. Invest. 58:761-765.

7. Bearn, A. G., B. Billing, and S. Sherlock. 1951. The effect of adrenaline and noradrenaline on hepatic blood flow and splanchnic carbohydrate metabolism in man. J. Physiol. (Lond.). 115:430-441.

8. Bessey, P. Q., J. M. Watters, T. T. Aoki, and D. W. Wilmore. 1984. Combined hormonal infusion simulates the metabolic response to injury. Ann. Surg. 200:264-281.

9. Kibler, R. F., W. R. Taylor, and J. D. Meyer. 1964. The effect of glucagon on net splanchnic balances of glucose, amino acid, nitrogen, urea, ketones, and oxygen in man. J. Clin. Invest. 43:904-915.

10. Legaspi, A., J. D. Albert, S. E. Calvano, M. F. Brennan, S. F. Lowry. 1985. Proteolysis of skeletal muscle in response to acute elevation of plasma cortisol in man. Surg. Forum. 36:16-18.

11. Waage, A., A. Halstensen, and T. Espevik. 1987. Association between tumor necrosis factor in serum and fatal outcome in patients with meningococcal disease. Lancet. i:355-357.

12. Scuderi, P., K. S. Lam, K. J. Ryan, E. Peterson, K. E. Sterling, P. R. Finley, C. G. Ray, D. J. Slymen, and S. E. Salmon. 1986. Raised levels of tumor necrosis factor in parasitic infections. Lancet. ii:13641365.
13. Tracey, K. J., S. F. Lowry, T. J. Fahey, Y. Fong, D. G. Hesse, B. Beutler, K. Manogue, S. E. Calvano, H. Wei, J. D. Albert, et al. 1987. Cachectin/tumor necrosis factor induces lethal septic shock and stress hormone responses in the dog. Surg. Gynecol. Obstet. 164:415-422.

14. Tracey, K. J., B. Beutler, S. F. Lowry, J. Merryweather, S. Wolpe, I. W. Milsark, R. J. Hariri, T. J. Fahey, A. Zentella, J. D. Albert, et al. 1986. Shock and tissue injury induced by recombinant human cachectin. Science (Wash. DC). 470:234-238.

15. Moldawer, L. L., C. Andersson, J. Gelin, C. Lonnroth, and K. Lundholm. 1988. Regulation of food intake and hepatic protein metabolism by recombinant-derived monokines. Am. J. Physiol. 254:G450-456.

16. Fong, Y., L. L. Moldawer, M. Marano, H. Wei, A. Barber, K. Manogue, K. J. Tracey, G. Kuo, D. A. Fischman, A. Cerami, et al. 1989. Cachectin/TNF or IL- $1 \alpha$ induces cachexia with redistribution of body proteins. Am. J. Physiol. 256:R659-R665.

17. Mathison, J. C., E. Wolfson, and R. J. Ulevitch. 1988. Participation of tumor necrosis factor in the mediation of gram negative bacterial lipopolysaccharide-induced injury in rabbits. J. Clin. Invest. 81:1925-1937.

18. Tracey, K. J., Y. Fong, D. G. Hesse, K. R. Manogue, A. T. Lee, G. C. Kuo, S. F. Lowry, and A. Cerami. 1987. Anti-cachectin/TNF monoclonal antibodies prevent septic shock during lethal bacteraemia. Nature (Lond.). 330:662-664.

19. Fong, Y., K. J. Tracey, L. L. Moldawer, D. G. Hesse, K. R. Manogue, J. S. Kenney, A. T. Lee, G. C. Kuo, A. C. Allison, S. F. Lowry, et al. 1989. Antibodies to cachectin/TNF reduce interleukin-1 $\beta$ and interleukin-6 appearance during lethal bacteremia. J. Exp. Med. 170:1627-1633.

20. Silen, M. L., D. G. Hesse, D. Felsen, L. L. Moldawer, S. E. Calvano, A. Cerami, and S. F. Lowry. 1989. Cachectin/tumor necrosis factor production by fetal and newborn rat hepatic macrophages. $J$. Pediatr. Surg. 24:34-38.

21. Hochstein, H. D., D. F. Mills, H. S. Outschoorn, and S. C. Rostogi. 1983. The processing and collaborative assay of a reference endotoxin. J. Biol. Stand. 11:251-260.

22. Wilmore, J. H., J. A. Davis, and A. C. Norton. 1976. An automated system for assessing metabolic and respiratory function during exercise. J. Appl. Physiol. 40:619-624.

23. Weir, J. B. deV. 1949. New methods for calculating metabolic rate with special reference to protein metabolism. J. Physiol. (Lond.). 109:1-9.

24. Sigdel, J. E. 1975. Venous occlusion plethysmography: basic principles and application. Biomed. Eng. (Berl.). 10:300-302.

25. Caesar, J., S. Shaldon, L. Chiandussi, L. Guevara, and S. Sherlock. 1961. The use of indocyanine green in the measurement of hepatic blood flow as a test of hepatic function. Clin. Sci. (Lond.). 21:43-57.

26. Wahren, J., P. Felig, and L. Hagenfeldt. 1976. Effect of protein ingestion on splanchnic metabolism in normal man and in patients with diabetes mellitus. J. Clin. Invest. 57:987-999.

27. Huggett, A. S., and D. A. Nixon. 1957. Use of glucose oxidase, peroxidase, and o-dianisidine in determination of blood and urinary glucose. Lancet ii:368-370.

28. Henry, R. J. 1968. Clinical Chemistry-Principles and Technics. Harper \& Row, Inc., New York. 664-666.

29. Dole, V. P., and H. Meinertz. 1960. Microdetermination of long-chain fatty acids in plasma and tissues. J. Biol. Chem. 235:25952599.

30. McGowan, M. W., J. D. Artiss, D. R. Strandbergh, and B. Zak. 1983. A peroxidase-coupled method for the colorimetric determination of serum triglycerides. Clin. Chem. 29:538-542.

31. Lee, P. L. Y. 1974. Single-column system for accelerated amino acid analysis of physiologic fluids using three lithium buffers. Biochem. Med. 10:107-112.

32. Calvano, S. E., J. Chiao, L. E. Reaves, A. C. Antonacci, and G. T. Shires. 1984. Changes in free and total levels of plasma cortisol 
and thyroxine following thermal injury in man. J. Burn Care Rehab. 5:143-151.

33. Soeldner, J. S., and D. Sloane. 1965. Critical variables in radioimmunoassay of serum insulin using the double antibody technique. Diabetes. 14:771-779.

34. Aquilar-Parada, A., A. M. Eisentraut, and R. H. Unger. 1969. Effects of starvation on plasma pancreatic glucagon. Diabetes. 18:717-723.

35. Passon, P. G., and J. D. Peuler. 1973. A simplified radiometric assay for plasma norepinephrine and epinephrine. Ann. Biochem. 51:618-631.

36. Hesse, D. G., K. J. Tracey, Y. Fong, K. R. Manogue, M. A. Palladino, A. Cerami, G. T. Shires, and S. F. Lowry. 1988. Cytokine appearance in human endotoxemia and primate bacteremia. Surg. Gynecol. Obstet. 166:147-153.

37. Kenney, J. S., M. P. Masada, E. M. Eugui, B. M. Delustro, M. A. Mulkins, and A. C. Allison. 1987. Monoclonal antibodies to human recombinant interleukin 1 (IL-1)beta: quantitation of IL-1 beta and inhibition of biological activity. J. Immunol. 138:4236-4242.

38. Aarden, L. A., E. R. DeGroot, O. L. Schaap, and P. Lansdorf. 1987. Production of hybridoma growth factor by human monocytes. Eur. J. Immunol. 17:1411-1416.

39. Dahn, M. S., P. Lange, K. Lobdell, B. Hans, L. A. Jacobs, and R. A. Mitchell. 1987. Splanchnic and total body oxygen consumption differences in septic and injured patients. Surgery. 101:69-80.

40. Dubois, E. F. 1924. Basal Metabolism in Health and Disease. Lea \& Febiger, Philadelphia. 311 pp.

41. Onen, K. H., O. L. Wade, and J. D. Bainey. 1956. Amino acids in hepatic venous and arterial blood. Lancet 271:1075-1076.

42. Starnes, H. F., R. S. Warren, M. Jeevanandam, J. L. Gabrilove, W. Larchian, H. F. Oettgen, and M. F. Brennan. 1988. Tumor necrosis factor and the acute metabolic response to tissue injury in man. J. Clin. Invest. 82:1321-1325.

43. Blick, M., S. A. Sherwin, M. Rosenbaum, and J. Gutterman. 1987. Phase I study of recombinant tumor necrosis factor in cancer patients. Cancer Res. 47:2986-2989.

44. Norton, L., G. Moore, and B. Eiseman. 1975. Liver failure in the postoperative patient: the role of sepsis and immunologic deficiency. Surgery. 78:6-13.

45. Imamura, M., and G. H. A. Clowes. 1975. Hepatic blood flow and oxygen consumption in starvation, sepsis, and septic shock. Surg. Gynecol. Obstet. 141:27-34.

46. Wilmore, D. W., C. W. Goodwin, L. H. Aulick, M. C. Powanda, A. D. Mason, and B. A. Pruitt. 1980. Effect of injury and infection on visceral metabolism and circulation. Ann. Surg. 192:491504.

47. Jepson, M. M., J. M. Pell, P. C. Bates, and D. C. Millward. 1986. The effects of endotoxemia on protein metabolism in skeletal muscle and liver of fed and fasted rats. Biochem. J. 235:329-336.

48. Morrison, D. C., and J. L. Ryan. 1987. Endotoxins and disease mechanisms. Annu. Rev. Med. 38:417-432.

49. Revhaug, A., H. R. Michie, J. M. Manson, J. M. Watters, C. A. Dinarello, S. M. Wolff, and D. W. Wilmore. 1988. Inhibition of cyclooxygenase attenuates the metabolic response to endotoxin in humans. Arch. Surg. 123:162-170.

50. Carpentier, Y. A., M. Jeevanandam, A. P. Robin, J. Nordenstrom, R. E. Burr, R. L. Leibel, J. Hirsch, D. H. Elwyn, and J. M. Kinney. 1984. Measurement of glycerol turnover by infusion of nonisotopic glycerol in normal and injured subjects. Am. J. Physiol. 247:E405-E411.

51. Nordenstrom, J., Y. A. Carpentier, J. Askanazi, A. P. Robin, D. H. Elwyn, T. W. Hensle, and J. M. Kinney. 1983. Free fatty acid mobilization and oxidation during total parenteral nutrition in trauma and infection. Ann. Surg. 198:725-735.

52. Gelfand, R. A., R. A. Defronzo, and R. Gusberg. 1983. Metabolic alterations associated with major injury or infection. In New Aspects of Clinical Nutrition. G. Kleinberger and E. Deutsch, editors S. Karger, Basel. 211-239.

53. Havel, R. J., J. P. Kane, E. O. Balasse, N. Segel, and L. V. Basso. 1970. Splanchnic metabolism of free fatty acids and production of triglycerides of very low density lipoproteins in normotriglyceridemic and hypertriglyceridemic humans. J. Clin. Invest. 49:2017-2035.

54. Lowry, S. F. 1986. Host metabolic response to injury. In Advances in Host Defense Mechanisms. J. I. Gallin, and A. S. Fauci, editors. Raven Press, New York. 169-190.

55. Simmons, P. S., J. M. Miles, J. E. Gerich, and M. W. Haymond. 1984. Increased proteolysis: an effect of increases in plasma cortisol within the physiologic range. J. Clin. Invest. 73:412-420.

56. Lee, M. D., A. Zentella, P. H. Pekala, and A. Cerami. 1987. Effect of endotoxin induced monokines on glucose metabolism in the muscle cell line L-6. Proc. Natl. Acad. Sci. USA. 84:2590-2594.

57. Meszaros, K., C. H. Lang, G. J. Bagby, and J. J. Spitzer. 1987. Tumor necrosis factor increases in vivo glucose utilization of macrophage-rich tissues. Biochem. Biophys. Res. Commun. 149:1-6.

58. Warren, R. S., D. B. Donner, H. F. Starnes, and M. F. Brennan. 1987. Modulation of endogenous hormone action by recombinant human tumor necrosis factor. Proc. Natl. Acad. Sci. USA. 84:86198622.

59. Feingold, K. R., and C. Grunfeld. 1987. Tumor necrosis factor-alpha stimulates hepatic lipogenesis in the rat in vivo. J. Clin. Invest. 80:184-190.

60. Warren, R. S., H. F. Starnes, J. L. Gabrilove, H. F. Oettgen, and M. F. Brennan. 1987. The acute metabolic effects of tumor necrosis factor administration. Arch. Surg. 122:1396-1400.

61. Ulich, T. R., K. Guo, and J. del Castillo. 1989. Endotoxin-induced cytokine gene expression in vivo. Am. J. Pathol. 134:11-14.

62. Takacs, L., E. J. Kovacs, M. R. Smith, H. A. Young, and S. K. Durum. 1988. Detection of IL- $1 \alpha$ and IL-1 $\beta$ gene expression by in situ hybridization. J. Immunol. 141:3081-3095.

63. Leist, T. P., K. Frei, S. Kam-Hansen, R. M. Zinkernagel, and A. Fontana. 1988. Tumor necrosis factor $\alpha$ in cerebrospinal fluid during bacterial, but not viral, meningitis. J. Exp. Med. 167:1743-1748.

64. Helfgott, D. C., S. B. Tatter, U. Santhanam, R. H. Clarick, N. Bhardwaj, L. T. May, and P. B. Sehgal. 1989. Multiple forms of IFNbeta 2/IL-6 in serum and body fluids during acute bacterial infection. J. Immunol. 142:948-953.

65. Nelson, S., G. J. Bagby, B. G. Bainton, L. A. Wilson, J. J. Thompson, and W. R. Summer. 1989. Compartmentalization of intraalveolar and systemic lipopolysaccharide-induced tumor necrosis factor and the pulmonary inflammatory response. J. Infect. Dis. 159:189-194.

66. Fong, Y., L. L. Moldawer, M. Marano, H. Wei, S. B. Tatter, R. H. Clarick, U. Santhanam, L. May, P. B. Sehgal, and S. F. Lowry. 1989. Endotoxemia elicits increased circulating $\beta_{2}$-interferon/interleukin-6 in man. J. Immunol. 142:2321-2324.

67. Kurzrock, R., M. F. Rohde, J. R. Quesada, S. H. Gianturco, W. A. Bradley, S. A. Sherwin, and J. W. Gutterman. 1986. Recombinant gamma interferon induces hypertriglyceridemia and inhibits post-heparin lipase activity in cancer patients. J. Exp. Med. 164:1093-1101.

68. Wolpe, S. D., G. Davatelis, B. Sherry, B. Beutler, D. G. Hesse, H. T. Nguyen, L. L. Moldawer, C. F. Nathan, S. F. Lowry, and A. Cerami. 1988. Macrophages secrete a novel heparin-binding protein with inflammatory and neutrophil chemokinetic properties. J. Exp. Med. 167:570-581. 